\title{
Data-Driven Analysis for Safe Ship Operation in Ports Using Quantile Regression Based on Generalized Additive Models and Deep Neural Network
}

\author{
Hyeong-Tak Lee ${ }^{1}$ (D), Hyun Yang ${ }^{2}$ and Ik-Soon Cho ${ }^{3, *(\mathbb{D})}$ \\ 1 Ocean Science and Technology School, Korea Maritime and Ocean University, Busan 49112, Korea; \\ gudxkr518@kmou.ac.kr \\ 2 Korea Ocean Satellite Center, Korea Institute of Ocean Science \& Technology, Busan 49112, Korea; \\ yanghyun@kiost.ac.kr \\ 3 Division of Navigation Convergence Studies, Korea Maritime and Ocean University, Busan 49112, Korea \\ * Correspondence: ischo@kmou.ac.kr; Tel.: +82-51-410-5072
}

Citation: Lee, H.-T.; Yang, H.; Cho, I.-S. Data-Driven Analysis for Safe Ship Operation in Ports Using Quantile Regression Based on Generalized Additive Models and Deep Neural Network. Sensors 2021, 21, 8254. https://doi.org/10.3390/ s21248254

Academic Editor: Itzik Klein

Received: 8 November 2021

Accepted: 8 December 2021

Published: 10 December 2021

Publisher's Note: MDPI stays neutral with regard to jurisdictional claims in published maps and institutional affiliations.

Copyright: (c) 2021 by the authors. Licensee MDPI, Basel, Switzerland. This article is an open access article distributed under the terms and conditions of the Creative Commons Attribution (CC BY) license (https:// creativecommons.org/licenses/by/ $4.0 /)$.

\begin{abstract}
Marine accidents in ports can cause loss of human life and property and have negative material and environmental impacts. In South Korea, due to a pier collision accident of a large container ship in Busan New Port of South Korea, the need for safe ship operation guidelines in ports emerged. Therefore, to support quantitative safe ship operation guidelines, ship trajectory data based on automatic information system information have been used. However, because this trajectory information is variable and uncertain due to various situations arising during a ship's navigation, there is a limit to deriving results through traditional regression analysis. Considering the characteristics of these data, we analyzed ship trajectories through quantile regression using two models based on generalized additive models and neural networks corresponding to deep learning. Among the automatic information system information, the speed over ground, course over ground, and ship's position were analyzed, and the model was evaluated based on quantile loss. Based on this study, it is possible to suggest safe operation guidelines for the position, speed, and course of the ship. In addition, the results of this work can be further developed as a manual for the in-port-autonomous operation of ships in the future.
\end{abstract}

Keywords: automatic information system; deep learning; deep neural network; generalized additive models; quantile regression; safe ship operation; ship trajectories

\section{Introduction}

Maritime accidents in ports not only cause loss of human life and physical damage to ships, but also have economic consequences for maritime transportation and environmental consequences in ports [1]. As a result of the introduction of increasingly massive ships, greater safety measures are required in the operation of ships in ports [2]. In recent years, maritime accidents resulting from human factors in the piloting process, such as the inability to control excessive speed of the ship in a timely manner or the inability to secure a sufficiently safe distance from the pier, have become frequent [3]. A typical example is the pier collision accident of a 13,900 TEU container ship that was entering Busan New Port in April 2020 [4]. In the accident, a gantry crane was completely destroyed and three were partially damaged. Considerable other damages and injuries to cargo workers were also incurred.

A special investigation report about this accident was prepared by the Korea Maritime Safety Tribunal (KMST) of the Ministry of Oceans and Fisheries in the Republic of Korea [3]. The role of a pilot with professional knowledge about a port is extremely important when a ship enters the port [5]. Accordingly, the report presented a proposal to prepare a standard pilot manual to minimize the possibility of accidents caused by human factors, such as 
the skill gap between pilots or differences in ship-handling methods. In particular, it is necessary to prepare safety procedures for ship operation, such as safe navigation in dangerous sections and safe velocity for pier approach, based on many piloting cases in the same port.

Ship trajectory data are required to collect information about various cases of piloting ships in a port. Trajectory data have become important for big-data analysis due to advances in science and technology, and are widely used for purposes such as target tracking, behavior analysis, and navigation [6]. Ship trajectory data can be collected using an automatic identification system (AIS). AIS data include ship navigation status information such as the position, speed over ground (SOG), and course over ground (COG) of the ship [7].

AIS ship trajectory data are a crucial data source in research on the safe operation of ships. Lee et al. extracted the vessel traffic route through quantitative analysis based on AIS data for the design of a safe route considering the ship characteristics [8]. Son et al. analyzed the range of the safe distance for ships sailing under a bridge across a waterway through AIS-based tracking [9]. Huang et al. analyzed the crossing-line and used Monte Carlo methods based on AIS data for navigation safety assessment for an approaching channel [10]. Active research is ongoing on the use of artificial intelligence techniques for ship trajectories based on big AIS data. Namgung and Kim predicted a ship's trajectory according to future tidal conditions using support vector regression to reduce maritime accidents [11]. Deep-learning-based ship trajectory prediction methods, such as long short-term memory (LSTM), for maritime navigation early warning and safety are being studied $[12,13]$. In some studies, clustering algorithms, such as density-based spatial clustering of applications with noise (DBSCAN), have been used to analyze the patterns of ship trajectories $[14,15]$. Lee et al. analyzed the patterns of the trajectories of ships entering and leaving Busan New Port using DBSCAN; their study was significant for analyzing the patterns of trajectories of ships in the port rather than in the ocean [16].

However, few studies have proposed quantitative analyses using ship trajectory data for safe operation in port. To analyze the safety procedures for ship operation, data such as the position, speed, and course of the ship, which are information included in the AIS, should be used [17]. Therefore, in this study, the ship's position, SOG, and COG data were regression analyzed to suggest appropriate guidelines for safe ship operation.

Ship operation in a port is affected by the size of the ship, the amount of traffic, the pilot's tendency, and environmental conditions [5], [18], thereby resulting in variable and uncertain ship trajectory data. If only the central tendency is considered when quantifying the datasets with such variability and uncertainty, the datasets cannot be properly represented. Therefore, the traditional regression analysis method that provides information on the effect of the independent variable on the mean value of the dependent variable has limitations with regard to framing guidelines for safe ship operation. Because of these limitations, quantile regression, which provides a regression model for conditional quantiles of the dependent variable, was used in this study. Quantile regression analysis focuses on the entire distribution by estimating the effect on the entire distribution of the response variable, instead of on the mean of the independent variable [19]. Because ship maneuvering is influenced by several factors, such as weather and traffic flow, proposing maneuvering guidelines based on an average of data is inappropriate. Therefore, in this study, quantile regression was applied to ship trajectory data, and the operating range of ships according to quantiles was determined to serve as a maneuvering guideline. Dinparast Djadid et al. used Bayesian quantile regression to model a driver's response time to reclaim control in automation [19]. Zou et al. used quantile regression to investigate factors influencing the time taken to clear road traffic incidents and reported that it can be used to make inferences about the effect of explanatory variables on different quantiles of the incidents' duration distribution [20].

The application of quantile regression in various means in combination with generalized additive models (GAMs) and deep learning is being explored. Murphy et al. 
analyzed water quality using GAMs combined with quantile regression [21]. Dinga et al. proposed an analysis method using quantile GAMs [22]. Quantile regression neural networks (QRNNs), which are based on deep learning and artificial intelligence techniques, are also being used in many studies. Further, with regard to load forecasting, research on analyzing the volatility and uncertainty of load data using QRNNs is ongoing [23,24], and in other fields, QRNNs have been applied to a breast cancer dataset [25].

The goal of this study was to provide guidelines for safe ship operation in ports by applying quantile regression using AIS-based ship trajectory data to resolve the volatility and uncertainty in ship maneuvering. Quantile regression in the analysis was utilized by combining GAMs and neural networks. Accordingly, we propose a quantitative standard guideline for safe ship operation in ports to minimize the possibility of ship accidents caused by human factors.

\section{Materials and Methods}

Figure 1 shows a flowchart of this study. First, AIS-based ship-arriving trajectories were collected at a target pier. The collected data were preprocessed to make the data suitable for analysis. Subsequently, the data characteristics were identified and visualized using basic data statistics. In the next step, the data were classified and modeled as the entering phase and berthing phase data according to the characteristics of the target pier. The technique utilizes GAMs and deep neural networks based on quantile regression. Further, a suitable model was selected through model evaluation and, finally, guidelines for safe ship operation in the port were proposed.

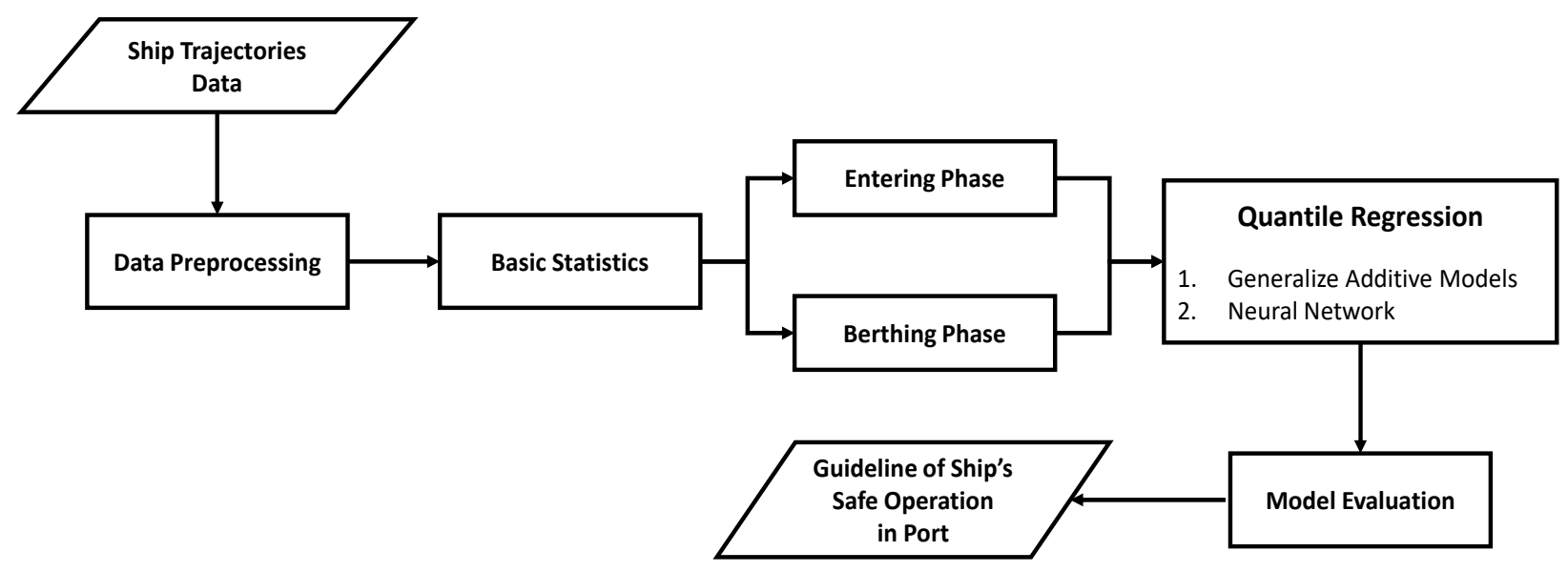

Figure 1. Flowchart of the study.

\subsection{Ship Trajectory Data}

We analyzed the data for Busan New Port in the Republic of Korea. The Busan New Port is a container ship port at which the aforementioned crane collision accident had occurred. The British Admiralty Chart of Busan New Port is shown in Figure 2.

Ship trajectory data were collected based on the AIS information of ships arriving at this port. In the 'Navigation Rules of Busan Port (Notice of Busan Regional Office of Oceans and Fisheries)', only the ship's speed, such as the passing speed for each section and the moving speed within the port, is presented as a procedure. However, to propose a ship maneuvering guideline in port, the route and ship's position under operation, including speed, should be given [16]. This port is relatively protected against the effects of weather compared to other ports, and the port is closed in the event of severe weather and poor visibility. Yoon et al. found that berthing of large containers at Busan New Port does not pose a significant risk, except in the event of severe weather [26]. Therefore, the variables considered in this study were the time and date, ship's position, SOG, and COG obtained from the AIS information. The data collection period was fixed considering the time of the gantry crane collision. Data were collected for four months from January 2020. The target 
ship type considered in the study was large container ships with a gross tonnage of 100k or more, similar to the ship involved in the accident. To consider all cases in which the ship was safely berthing, the weather conditions for the period were not separated. The details of the collected data are summarized in Table 1.

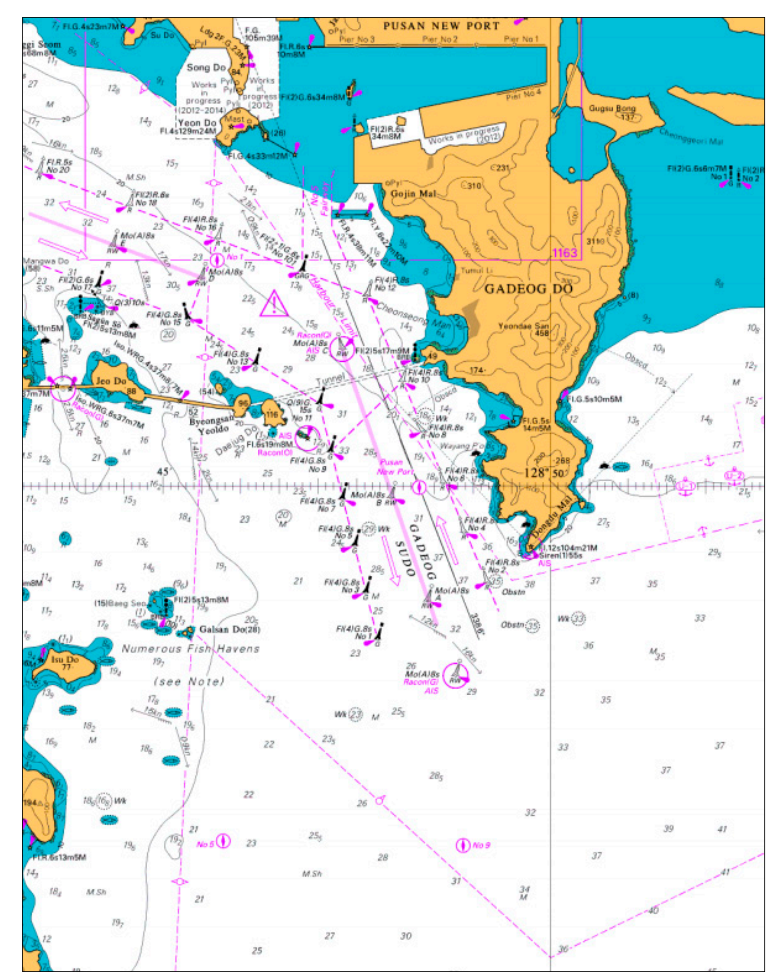

Figure 2. Geographical characteristics of Busan New Port: British Admiralty Chart.

Table 1. Characteristics of AIS data for analysis.

\begin{tabular}{cc}
\hline Categorization & AIS Information \\
\hline Period & 1 January 2020-30 April 2020 \\
Collection Area & Latitude 034.8 N-035.1 N \\
& Longitude 128.7 E-129.0 E \\
(Around Busan New Port) \\
Pier & Pier 2 No. 4 \\
& Pier 2 No. 5 \\
Ship Type & Pier 3 No. 1 \\
Size of ship & Container Ship \\
& Gross tonnage 100-220k \\
Information & Ship's position (latitude, longitude) \\
& Speed over Ground (knots) \\
& Course over Ground (degree) \\
\hline
\end{tabular}

\subsection{Data Preprocessing and Statistics}

In terms of data mining, data preprocessing is an essential step for improving the performance of analysis models [27]. As AIS data have information errors and reception errors due to receiving sensitivity about ships, preprocessing through data deletion is essential [28]. In addition, AIS data are characterized by different data reception intervals depending on the speed and changing course of the ship [29]. For example, the dynamic information of Class-A AIS used by SOLAS (International Convention for the Safety of Life at Sea) ships is received at intervals of $10 \mathrm{~s}$ for ships sailing under 14 knots, and at intervals of $3.3 \mathrm{~s}$ when the ship changes its course. In addition, because the arrival time of each ship is different, it is necessary to unify the unit used for the change in position 
with time when analyzing ship trajectories. Therefore, in this study, the data-cleaning and data-scaling methods were applied for data preprocessing.

Data cleaning is a preprocessing method that deletes noisy data and missing values to make the data suitable for analysis [27]. Missing values caused by AIS errors were removed using the list-wise delete method [30]. A ship entering Busan New Port was preprocessed with the AIS data from the position corresponding to maneuvering from the pilot station to the berthing. Data before the pilot station do not have regularities such as drifting and anchoring, and the port entry of the ship starts when the pilot is on board. Hence, the data cleansing was performed for latitude $34.93^{\circ} \mathrm{N}$.

Data scaling is the process of standardizing data units. When analyzing data, the data should be normalized to avoid any error in the analysis results due to differences in units [27]. In this study, min-max normalization was used as the data-scaling methods. When the information of each ship is defined as $S(x)$, the time corresponding to the starting point of the section is defined as $S\left(x_{\min }\right)$ and the last point as $S\left(x_{\max }\right)$, and the normalization proceeds as shown in Equation (1):

$$
\text { MinMax normalization }=\frac{S(x)-S\left(x_{\min }\right)}{S\left(x_{\max }\right)-S\left(x_{\min }\right)}
$$

The number of vessel arrivals in the ship trajectory dataset was 50 in this study. For the middle of the berth at the target pier of Busan New Port at the time, a ship can dock at the pier after passing a small island called Todo. When a ship passes Todo, it is classified as a case of berthing by passing to the left or a case of berthing by passing to the right. The frequency results are listed in Table 2.

Table 2. Number of times and the sides on which ships passed Todo.

\begin{tabular}{|c|c|c|c|c|}
\hline \multirow{2}{*}{$\begin{array}{c}\text { Todo } \\
\text { Passing }\end{array}$} & \multicolumn{3}{|c|}{ Pier } & \multirow[b]{2}{*}{ Total } \\
\hline & $\begin{array}{l}\text { Pier } 2 \\
\text { No. } 4\end{array}$ & $\begin{array}{l}\text { Pier } 2 \\
\text { No. } 5\end{array}$ & $\begin{array}{l}\text { Pier } 3 \\
\text { No. } 1\end{array}$ & \\
\hline Left & 5 & 17 & 1 & 23 \\
\hline Right & 23 & 4 & - & 27 \\
\hline
\end{tabular}

The purpose of this study was to propose a maneuvering guideline by analyzing the ranges according to quantiles for SOG, COG, and ship's position in the entire ship trajectory data. Therefore, cross-validation such as dividing into training and testing datasets was not conducted.

\subsection{Quantile Regression}

Multiple linear regression is a basic and standard approach that uses the values of multiple variables to describe or predict the mean value of a scale outcome. In contrast, quantile regression models the relationship between a set of independent variables and a specific percentile (or "quantile") of a dependent variable; that is, quantile regression is a linear model for the conditional $\tau$ quantile of the dependent variable, unlike the traditional regression analysis method that provides information on the influence of the independent variable on the mean value of the dependent variable [31]. This regression model is closely related to the model for the conditional median, and it is possible to estimate the conditional median of predictions and data by minimizing the mean absolute error [32]. The conditional quantiles of the distribution can be obtained by applying an asymmetric weight using the tilted absolute value function.

The tilted absolute value function is also called the pinball loss function and is as shown in Equation (2):

$$
\rho_{\tau}(u)=\left\{\begin{array}{cc}
\tau u & \text { if } u \geq 0 \\
(\tau-1) u & \text { if } u<0
\end{array}\right.
$$


where $0<\tau<1$. Assuming that the analysis variable is $x_{i}(t)(i=1, \ldots, I)$, the slope is $m_{i}$, and the intercept is $b$, the linear regression analysis formula for the $\tau$ quantile $\hat{y}_{t}$ is as shown in Equation (3):

$$
\hat{y}_{\tau}=\sum_{i=1}^{I} m_{i} x_{i}(t)+b
$$

Here, when the observation value at time $t$ is defined as $y(t)(t=1, \ldots, N)$, the equation for estimating the quantile regression error function by minimizing the quantile loss function is as shown in Equation (4):

$$
E_{\tau}=\frac{1}{N} \sum_{t=1}^{N} \rho_{\tau}\left(y(t)-\hat{y}_{\tau}(t)\right)
$$

In general, quantile regression is applied to a continuous variable and applied to a linear model, but it can also be applied when the parameter is nonlinear [33]. Such quantile regression can be used to obtain the confidence interval for the analysis result of the model. This regression is suitable for this study because it is less sensitive to outliers [34].

\subsection{Genealized Additive Models}

A GAM is a statistical model that mixed the properties of the generalized linear model with the additive model, and is a linear model that allows nonlinear functions of each variable using a smoothing function [35]. GAMs relax the constraint that the relationship must be a simple weighted sum, and instead assumes that the result can be modeled as a sum of arbitrary features of each feature. GAMs are generally suitable for establishing relationships between complex types of data that cannot be easily represented by linear or nonlinear models or for analyzing models without any special conditions. Therefore, it is appropriate to use GAMs because the ship trajectory data used in this study have uncertainty and volatility.

The general formula for multiple linear regression models is shown in Equation (5):

$$
y_{i}=\beta_{0}+\beta_{1} \chi_{i 1}+\beta_{2} \chi_{i 2}+\cdots+\beta_{p} \chi_{i p}+\epsilon_{i}
$$

To consider the nonlinear relationship between each explanatory variable and the response variable, we replace $\beta_{j} \chi_{i j}$ with the smooth nonlinear function $f_{j}\left(x_{i j}\right)$ in the multiple linear regression model to obtain Equation (6):

$$
y_{i}=\beta_{0}+f_{1}\left(x_{i 1}\right)+f_{1}\left(x_{i 1}\right)+\cdots+f_{p}\left(x_{i p}\right)+\epsilon_{i}
$$

Equation (6) can be rewritten as Equation (7):

$$
y_{i}=\beta_{0}+\sum_{j=1}^{p} f_{j}\left(x_{i j}\right)+\epsilon_{i}
$$

In this case, $f_{j}$ is an arbitrary function of each explanatory variable $x_{i j}$, and a nonparametric smoothing function is used [36]. Notably, GAMs are data based, not model based, and the fitted values of the results are not derived from an a priori model. Further, as there is no limitation of the shapes available in the parameter class, the data can determine the shape of the response curve. Therefore, this method can provide suitable results for analyzing ship trajectories.

\subsection{Quantile Regression Newral Network}

The artificial neural network is a suitable model for multiple regression problems with nonlinear transformations through complex linkages and activation functions of variables [37]. However, because the existing neural network only provides one output result at a time, it is not possible to derive prediction results according to quantiles [25]. Therefore, 
a QRNN was proposed. In particular, because NNs can output accurate information based on complex data, it was used to analyze ship trajectory data in this study. The hidden layer of the neural network is dense and connected by nodes. The output of the hidden layer is obtained by applying an activation function between the input value, the weight of the hidden layer, and the bias of the hidden layer [38]. When the input data value is $x_{j}(j=1,2, \ldots, J)$, the output of the $k^{\text {th }}(k=1,2, \ldots, K)$ node for the first hidden layer is as shown in Equation (8):

$$
g_{k}=f_{1}\left(\sum_{j=1}^{J} x_{j} w_{j k}^{(h)}+b_{k}^{(h)}\right)
$$

The output of the $l^{\text {th }}(l=1,2, \ldots, L)$ node in the second hidden layer is as shown in Equation (9):

$$
h_{l}=f_{2}\left(\sum_{k=1}^{K} g_{j} w_{k l}^{(h)}+b_{l}^{(h)}\right)
$$

where $f_{1}$ and $f_{2}$ denote activation functions, and $w^{(h)}$ and $b^{(h)}$ denote the weight and bias of the hidden layer, respectively. The output layer of the neural network can be expressed as shown in Equation (10) as a single node with a linear activation function that estimates the $\tau^{\text {th }}$ quantile for the $i^{\text {th }}$ subject:

$$
\hat{Q}_{i}^{(\tau)}=\sum_{l=1}^{L} h_{l} w_{l}^{(o)}+b^{(o)}
$$

Here, $w^{(o)}$ and $b^{(o)}$ represent the weight and bias of the output layer, respectively. The basic model architecture of the QRNN is shown in Figure 3. In this study, the number of hidden layers and neurons was investigated in each case to determine the best model.

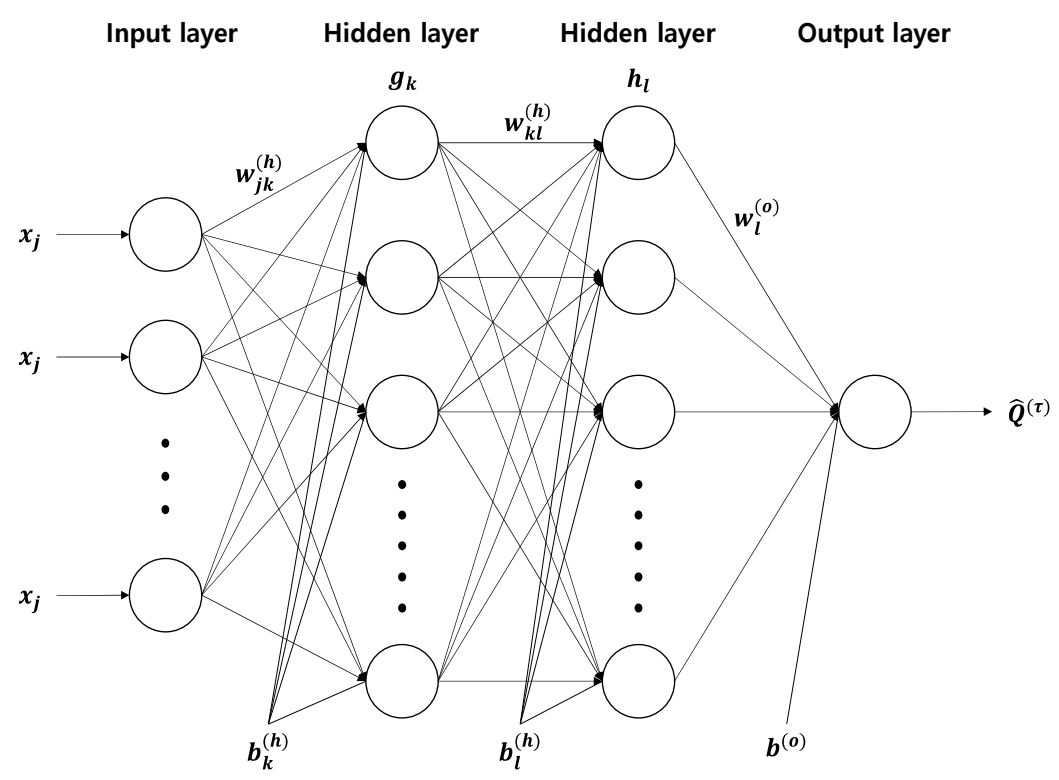

Figure 3. Overview of the quantile regression neural network (QRNN) architecture used in this study.

In this study, the Exponential Linear Unit (ELU) was used as the activation function. The ELU can increase the learning speed and classification accuracy of the deep neural network [39]. The ELU outputs the input value without refinement in the positive part to avoid the problem of gradient loss. In the Rectified Linear Unit (ReLU), which is the most widely used among neural network activation functions, the negative part of the function graph is in the form of unsaturation; in contrast, in the ELU, this part is in the form of saturation. 
The loss function used in the QRNN model was applied as a quantile loss value, as shown in Equation (4). In addition, the optimizer used the Adaptive Moment Estimation (Adam). Adam has an advantage over previous optimizers because it uses different sizes of updates for each parameter [40].

\subsection{Model Evaluation}

In this study, for the model evaluation of quantile GAMs and the QRNN, the quantile loss was used as the evaluation index [41]. In general regression analysis, if the mean absolute error (MAE), which is a representative index for evaluating the accuracy of the outcome variable, is minimized, the median regression line (0.5-quantile) is obtained. The quantile loss is the weighted MAE calculated to determine the $\tau$-quantile. Therefore, this index is suitable for evaluating quantile regression. The quantile loss is defined as shown in Equation (11):

$$
\begin{gathered}
\operatorname{Loss}(\tau)=\frac{1}{N} \sum_{i=1}^{N} \rho_{\tau}\left(y_{i}(\tau \mid x)-\hat{y}_{i}(\tau \mid x)\right) \\
\operatorname{MAE}(\tau)=\frac{1}{N} \sum_{i=1}^{N}\left|y_{i}(\tau \mid x)-\hat{y}_{i}(\tau \mid x)\right|
\end{gathered}
$$

where $\hat{y}_{i}(\tau \mid x)$ is the prediction of the true conditional quantile $y_{i}(\tau \mid x)$. Loss $(\tau)$ depends on asymmetric loss, as shown in Equation (4), and the smaller the measured value of $\operatorname{Loss}(\tau)$, the better the method.

\section{Experiments and Results}

In the experiments, modeling was performed using quantile GAMs and a QRNN with the constructed data. In addition, a suitable model was selected by evaluating the model performances. The experimental platform was a PC terminal, and the programming implementation of the model was completed using Python 3.7.3, pygam 0.8.0, and TensorFlow 1.15.0.

\subsection{Data Preprocessing and Statistics}

The AIS-based ship trajectories data were collected and then preprocessed to make them suitable for application for the quantile regression model. Cleaning was completed based on the pilot station latitude of $34.93^{\circ} \mathrm{N}$, and the ship's position, SOG, and COG data were normalized. The normalization or scaling result was input during the modeling with GAMs and the QRNN. Table 3 summarizes the minimum and maximum values for each datum; values normalized to a value between 0 and 1 were multiplied by 100 for ensuring the clarity of analysis results and expressed as a value between 0 and 100.

\begin{tabular}{|c|c|c|c|c|c|c|c|c|c|}
\hline \multirow{2}{*}{\multicolumn{2}{|c|}{ Phase }} & \multicolumn{2}{|c|}{$\begin{array}{c}\text { Speed over Ground } \\
\text { (Knots) }\end{array}$} & \multicolumn{2}{|c|}{$\begin{array}{l}\text { Course Over Ground } \\
\text { (Degree) }\end{array}$} & \multicolumn{2}{|c|}{ Longitude (East) } & \multicolumn{2}{|c|}{ Latitude (North) } \\
\hline & & Min & Mas & Min & Max & Min & Max & Min & Max \\
\hline \multicolumn{2}{|c|}{ Entering Phase } & 0.9 & 14.4 & 293.5 & $\begin{array}{c}007.8 \\
(367.8)\end{array}$ & 128.780 & 128.877 & 34.930 & 35.050 \\
\hline \multirow{2}{*}{$\begin{array}{l}\text { Berthing } \\
\text { Phase }\end{array}$} & Left & 0.0 & 12.0 & 184.5 & $\begin{array}{c}179.8 \\
(539.8)\end{array}$ & 128.781 & 128.805 & 35.050 & 35.078 \\
\hline & Right & 0.0 & 10.2 & 191.3 & $\begin{array}{l}173.7 \\
(533.7)\end{array}$ & 128.781 & 128.811 & 35.050 & 35.078 \\
\hline
\end{tabular}

Table 3. Results of the minimum and maximum values of each parameter for normalization.

A visualization of the preprocessed dataset is shown in Figure 4. To enter Busan New Port, the ship enters the waterway, Gadeog Sudo, after a pilot experienced in berthing at the port has boarded the ship. The arriving vessel must navigate to the right side of Gadeog Sudo. After the vessel has passed the Gadeog Sudo, it will pass through the breakwater to 
access the pier. Accordingly, based on the latitude $34.05^{\circ} \mathrm{N}$ point passing through the east breakwater, the ship trajectories in the dataset were classified into the entering phase and berthing phase. In the berthing phase, the ship employs a tug boat to control the ship's speed and course. The ships pass by Todo to berth at the target pier. The ship trajectory data used in this study show that ships navigate toward the north according to the passage of time. Therefore, in this study, the SOG, COG, and longitude were analyzed based on changes in the latitude.

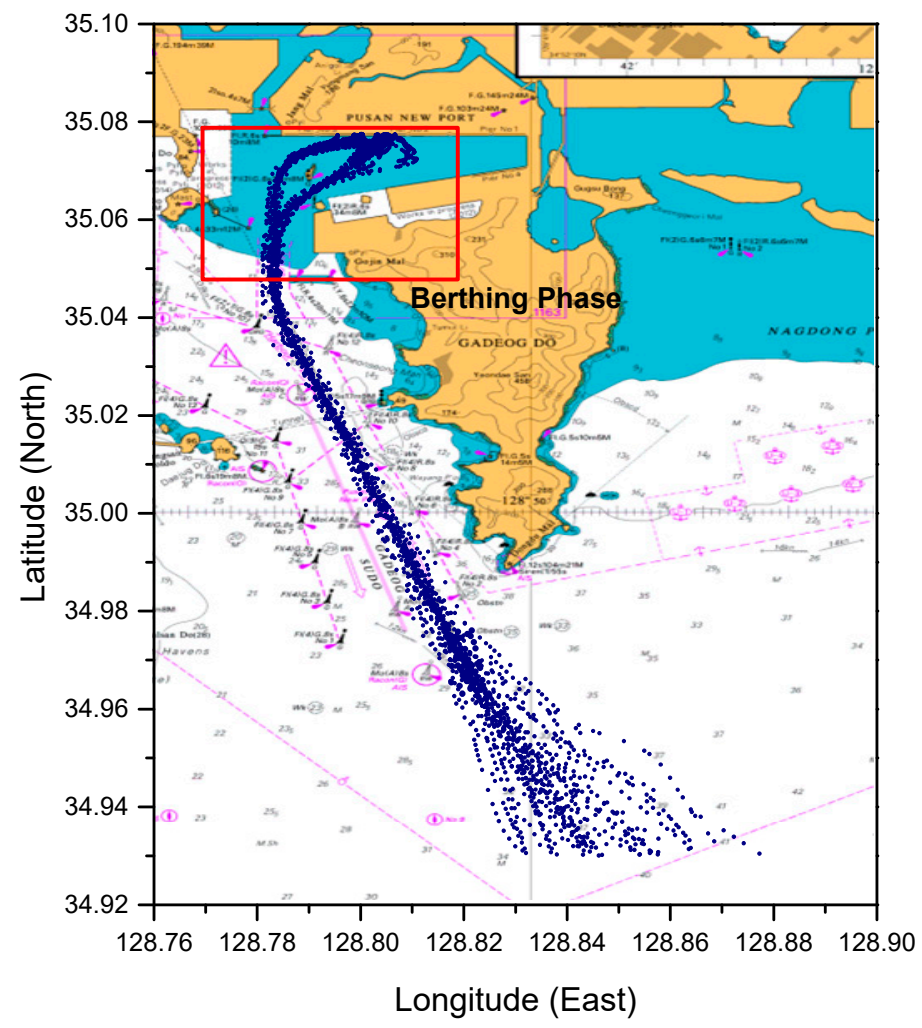

Figure 4. Ship trajectory data plotted on the British Admiralty Chart after completing the preprocessing.

A basic statistic was considered to understand the characteristics of AIS information for the entire process of the arrival of a ship. To understand the changes in the SOG, COG, and longitude information according to the latitude, the scatter data of 50 ships were connected with a line and visualized as a line plot, as shown in Figure 5. In addition, from the starting point of ship trajectories, i.e., latitude $34.93^{\circ} \mathrm{N}$, the characteristics of the dataset were visualized by a boxplot in 0.05 units. Figure 5 a shows the changes in the SOG: the SOG decreases in the latitude range of $34.97^{\circ} \mathrm{N}-34.98^{\circ} \mathrm{N}$ as the ships enter Gadeog Sudo. Thereafter, the SOG gradually increases as the ships pass through Gadeog Sudo, and then decrease to allow berthing after completing the passage through Gadeog Sudo. Figure 5b shows the changes in COG. The analysis showed that ships generally maneuvered north before the berthing phase. Thereafter, the courses can be classified based on two tendencies when passing by Todo and, just before berthing, a large deviation appears because vessels are precisely maneuvered using a tugboat and an engine. In Figure $5 c$, which shows the change in longitude, the y-axis is reversed for visual understanding. The descriptive statistics shown by grouping the ship trajectories data into 0.05-units of latitude are summarized in Table 4. Although the characteristics of the dataset can be identified through basic statistics, there is a limit to analyzing ship trajectories with volatility and uncertainty for the purpose of this study. Therefore, the results were derived using quantile GAMs and the QRNN. 


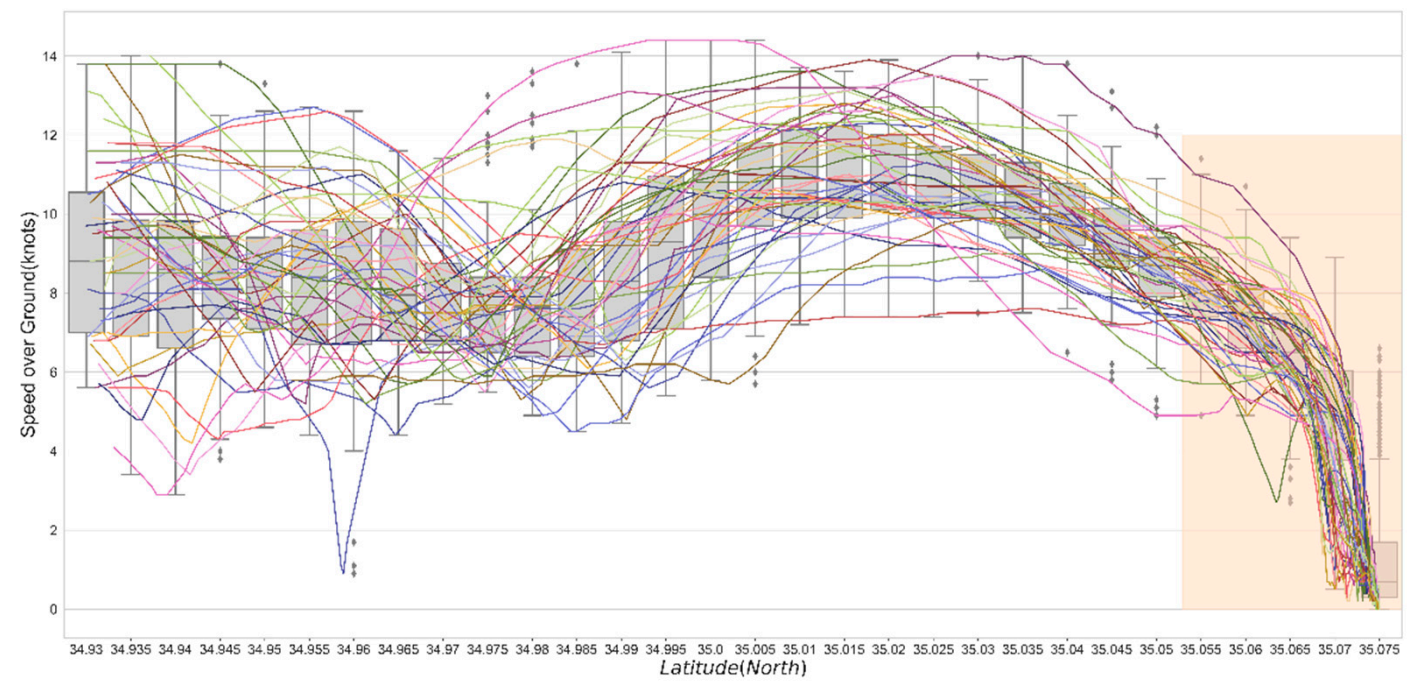

(a)

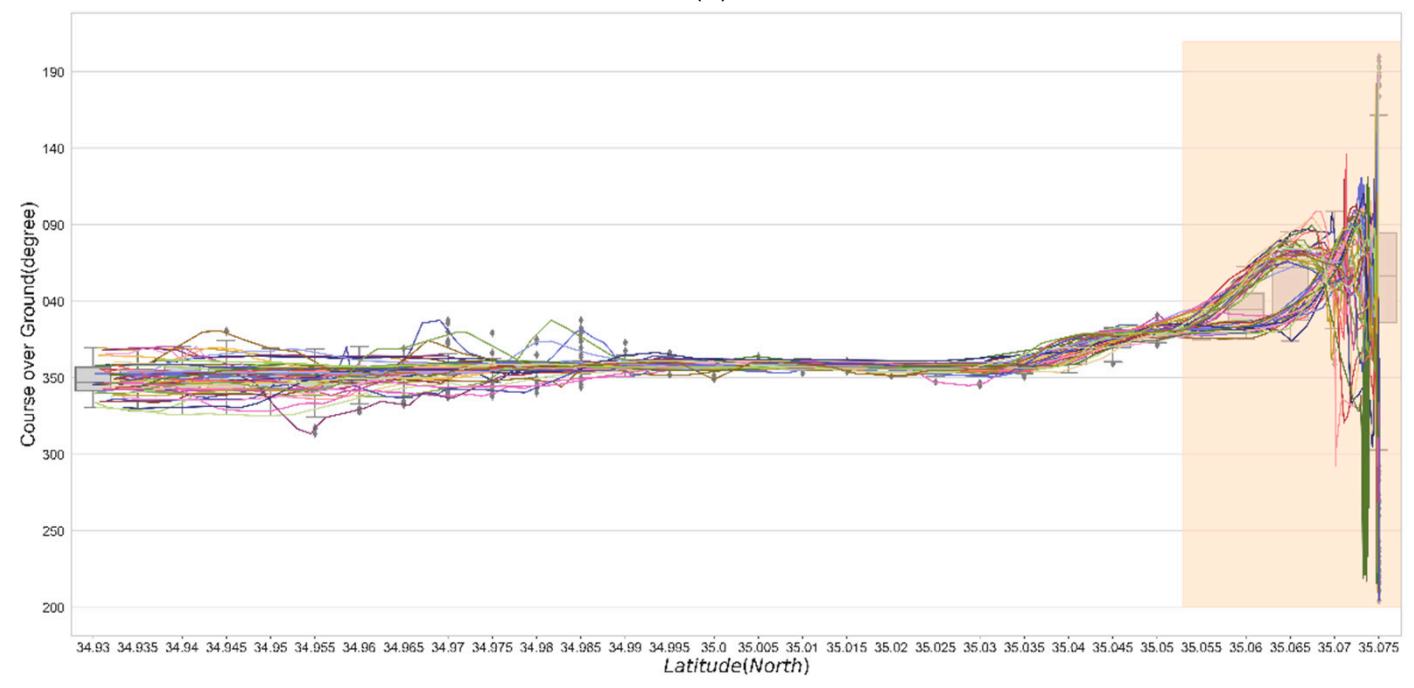

(b)

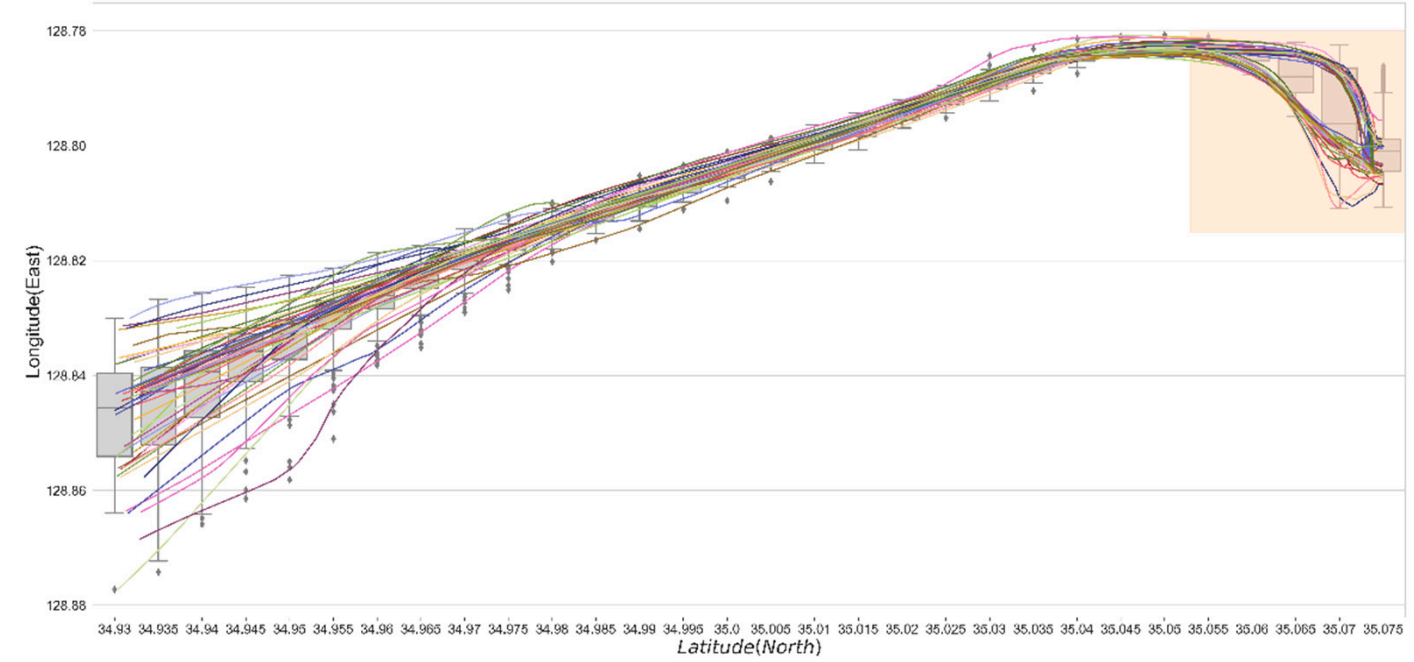

(c)

Figure 5. Visualization of ship trajectory data into boxplot and line plot based on latitude: (a) speed over ground (SOG); (b) course over ground (COG); and (c) longitude. The berthing phase part is marked by shading. 
Table 4. Descriptive statistics for ship trajectory data.

\begin{tabular}{ccccccc}
\hline & \multicolumn{2}{c}{ SOG $^{2}$} & \multicolumn{2}{c}{ COG $^{3}$} & \multicolumn{2}{c}{ Longitude } \\
\cline { 2 - 7 } Troup $^{\mathbf{1}}$ & Mean & Std. & Mean & Std. & Mean & Std. \\
\hline 34.930 & 9.07 & 2.28 & 329.03 & 10.40 & 128.85 & 0.01 \\
34.935 & 8.45 & 2.44 & 328.95 & 10.23 & 128.85 & 0.01 \\
34.940 & 8.29 & 2.53 & 330.16 & 11.00 & 128.84 & 0.01 \\
34.945 & 8.44 & 2.13 & 330.19 & 11.70 & 128.84 & 0.01 \\
34.950 & 8.30 & 1.92 & 329.10 & 10.90 & 128.83 & 0.01 \\
34.955 & 8.24 & 1.94 & 328.82 & 10.83 & 128.83 & 0.01 \\
34.960 & 8.11 & 2.19 & 330.97 & 8.15 & 128.83 & 0.01 \\
34.965 & 8.11 & 1.78 & 332.45 & 7.59 & 128.82 & 0.01 \\
34.970 & 7.76 & 1.49 & 334.94 & 9.22 & 128.82 & 0.01 \\
34.975 & 7.69 & 1.65 & 334.95 & 6.53 & 128.82 & 0.01 \\
34.980 & 7.78 & 1.92 & 336.18 & 4.86 & 128.81 & 0.01 \\
34.985 & 7.79 & 1.88 & 338.68 & 7.14 & 128.81 & 0.01 \\
34.990 & 8.42 & 2.08 & 338.17 & 3.23 & 128.81 & 0.01 \\
34.995 & 9.27 & 2.36 & 338.42 & 2.60 & 128.81 & 0.01 \\
35.000 & 9.80 & 1.85 & 338.19 & 2.35 & 128.80 & 0.01 \\
35.005 & 10.53 & 1.79 & 338.59 & 1.68 & 128.80 & 0.01 \\
35.010 & 10.73 & 1.67 & 338.54 & 1.76 & 128.80 & 0.01 \\
35.015 & 10.97 & 1.42 & 337.68 & 1.57 & 128.80 & 0.01 \\
35.020 & 10.87 & 1.48 & 336.63 & 2.16 & 128.79 & 0.01 \\
35.025 & 10.66 & 1.34 & 336.27 & 2.47 & 128.79 & 0.01 \\
35.030 & 10.60 & 1.31 & 335.80 & 2.77 & 128.79 & 0.01 \\
35.035 & 10.43 & 1.43 & 337.06 & 2.76 & 128.79 & 0.01 \\
35.040 & 10.06 & 1.28 & 343.79 & 5.73 & 128.78 & 0.01 \\
35.045 & 9.38 & 1.36 & 353.08 & 4.86 & 128.78 & 0.01 \\
35.050 & 8.62 & 1.26 & 359.07 & 3.30 & 128.78 & 0.01 \\
35.055 & 8.16 & 1.16 & 363.07 & 4.79 & 128.78 & 0.01 \\
35.060 & 7.48 & 1.15 & 014.97 & 12.56 & 128.78 & 0.01 \\
35.065 & 6.65 & 1.19 & 032.51 & 21.38 & 128.79 & 0.01 \\
35.070 & 4.77 & 1.86 & 042.87 & 18.27 & 128.79 & 0.01 \\
35.075 & 1.17 & 1.20 & 031.33 & 46.24 & 128.80 & 0.01 \\
\hline
\end{tabular}

${ }^{1}$ Group units are latitude (North) $\pm 0.025,{ }^{2}$ speed over ground (knots), ${ }^{3}$ course over ground (degree).

\subsection{Modeling and Evaluation}

Before modeling to suggest guidelines for safe ship operation in a port, the dataset was divided into data corresponding to the entering phase and those corresponding to the berthing phase. Depending on the berthing phase, the ships passing by Todo were classified into those that maneuvered to the left and those that maneuvered to the right. This classification was performed to suggest clear and specific guidelines for each section through which the ships enter Busan New Port. In this study, the dependent variable was the latitude, and the independent variables were SOG, COG, and longitude. The ship trajectory data divided into three categories were modeled according to each independent variable.

\subsubsection{Modeling of Generalized Additive Models}

Figure 6 shows the results of quantile regression of the dataset using GAMs. All results of quantile modeling using GAMs were statistically significant ( $p$-value $<0.001$ ). Based on the minimum and maximum values listed in Table 3 , the x-axis represents the scaled latitude, and the $y$-axis represents the result of scaling each information. Figure $6 a-c$ shows the results of applying the SOG information to the GAMs by applying the entering phase, the berthing phase of passing by Todo to the left, and the berthing phase of passing by Todo to the right, respectively. Figure $6 \mathrm{~d}-\mathrm{f}$ shows the $\mathrm{COG}$, and Figure $6 \mathrm{~g}-\mathrm{i}$ shows the analysis results for longitude. In particular, GAMs are characterized by smooth lines due to the application of the smoothing function. 


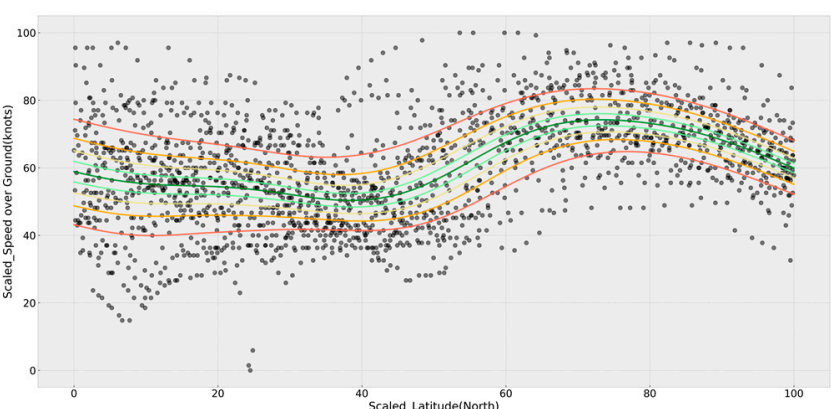

(a)

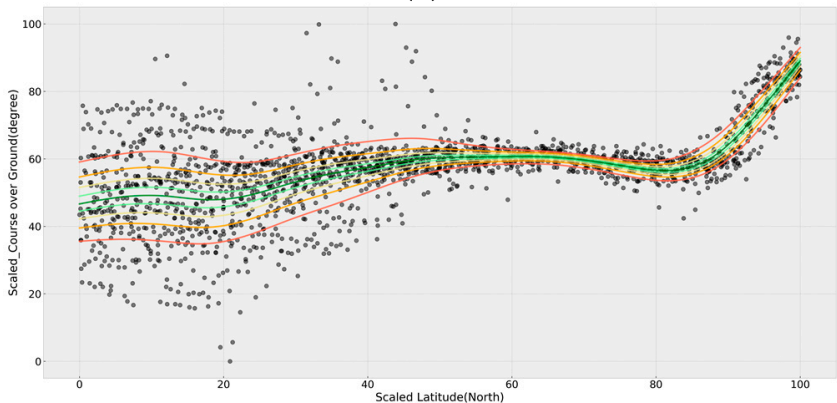

(d)

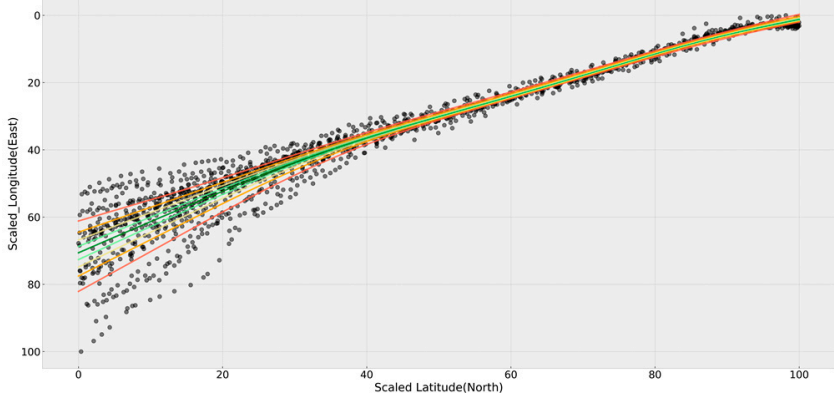

(g)

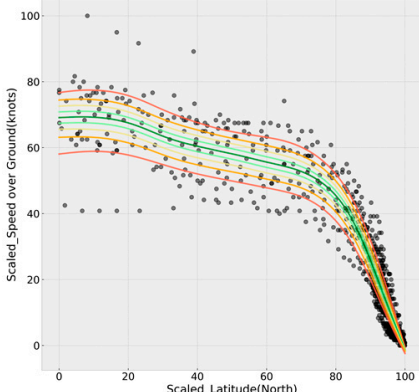

(b)

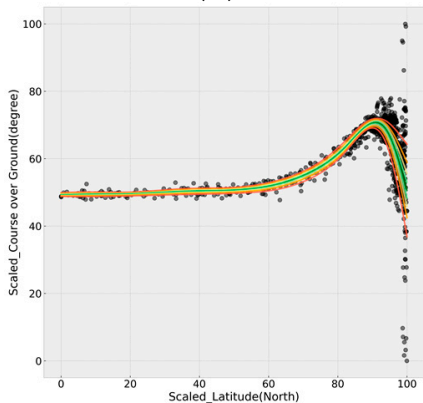

(e)

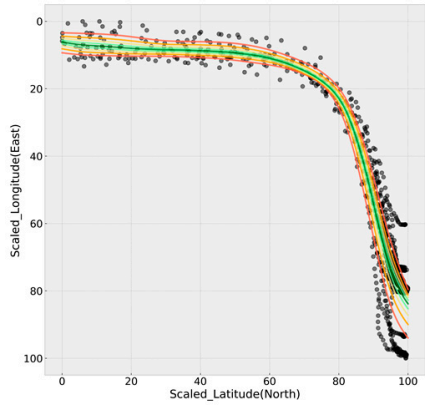

(h)

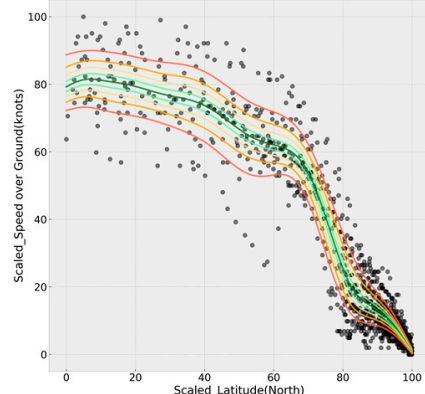

(c)

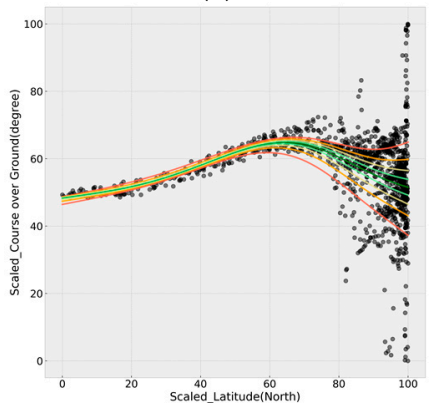

(f)

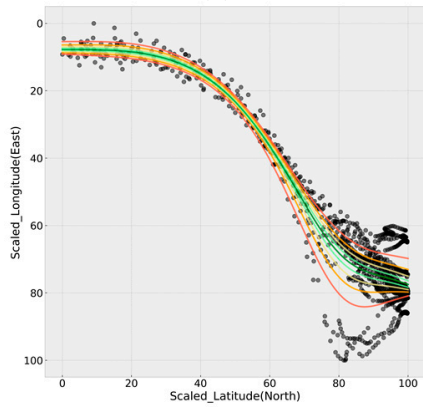

(i)

Figure 6. Results of modeling with quantile generalized additive models (GAMs): (a,d,g) SOG, COG, and longitude respectively, in the entering phase; (b,e,h) SOG, COG, and longitude, respectively, when passing Todo to the left in the berthing phase; and (c,f,i) SOG, COG, and longitude, respectively, when passing Todo to the right, in the berthing phase. Furthermore, 0.1 and 0.9 quantiles are indicated by red, 0.2 and 0.8 by orange, 0.3 and 0.7 by yellow, 0.4 and 0.6 by yellow-green, and 0.5 by green lines.

\subsubsection{Modeling of the Quantile Regression Neural Network}

By comparison, the QRNN is slightly more affected by the distribution of the dataset than GAMs, and hence, the QRNN fitting line is not smooth. The number of hidden layers and the appropriate number of neurons in each hidden layer in the QRNN model determined the most optimal model among 16 cases (Table 5). The QRNN corresponding to 0.5-quantile was modeled for each case using the SOG data from the entering phase, and the optimal model was determined using the MAE. Therefore, according to the results of Table 5, four hidden layers and 16 neurons were determined as the most optimal QRNN modeling. Further, the computational time required was the longest at $15 \mathrm{~s}$, although the analysis was fast and there was minor difference from the other cases. Figure 7 shows the result of visualizing QRNN modeling and shows the analysis results of SOG, COG, and longitude for each phase. 


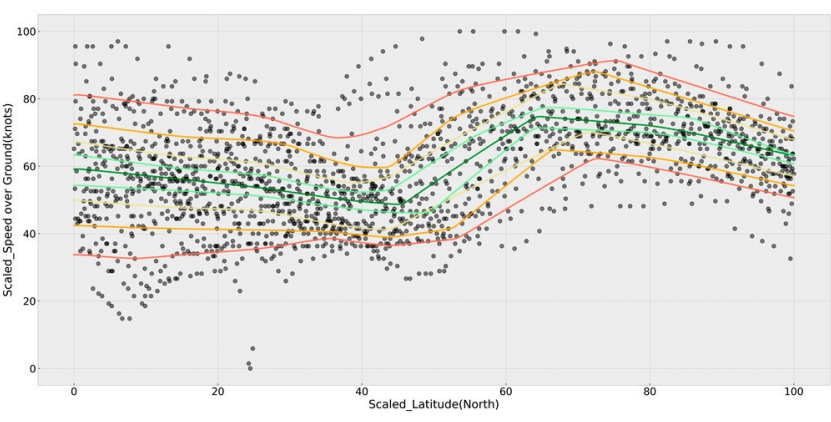

(a)

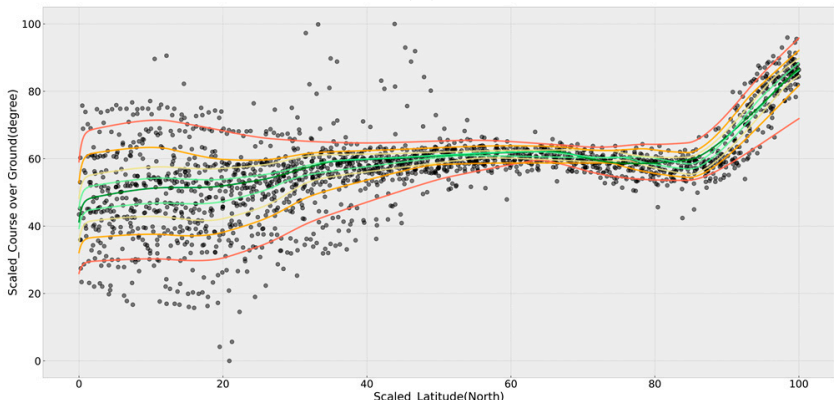

(d)

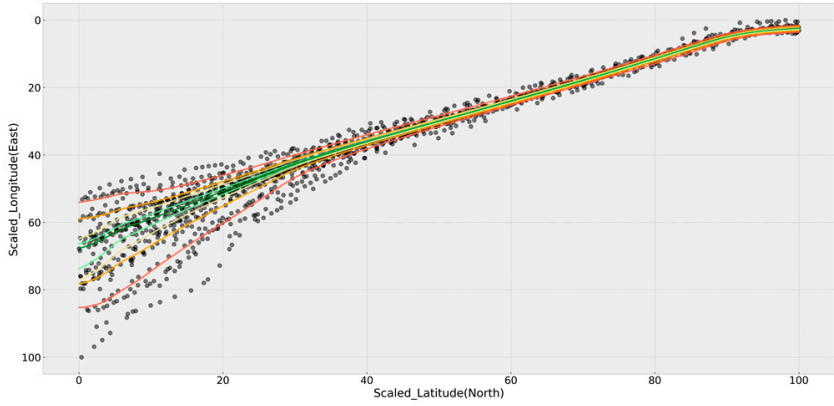

(g)

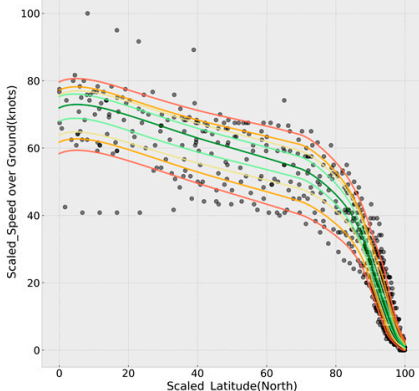

(b)

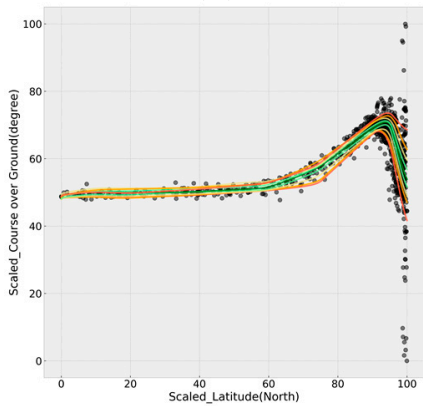

(e)

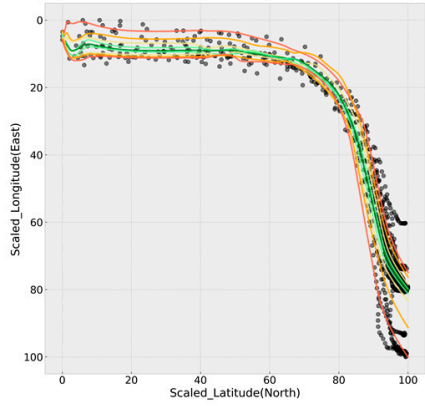

(h)

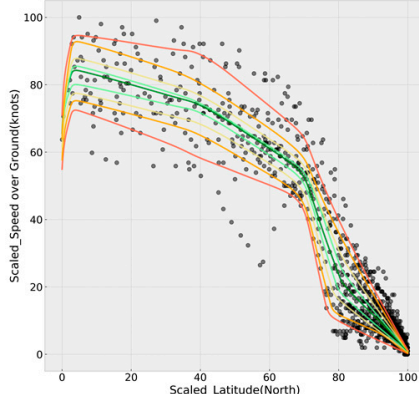

(c)

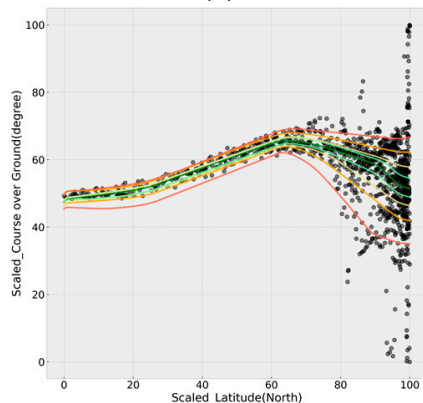

(f)

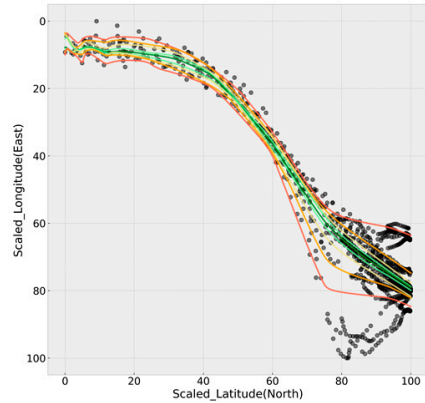

(i)

Figure 7. Results of QRNN modeling: (a,d,g) SOG, COG, and longitude, respectively, in the entering phase; (b,e,h) SOG, COG, and longitude, respectively, when passing Todo to the left in the berthing phase; and (c,f,i) SOG, COG, and longitude, respectively, when passing Todo to the right in the berthing phase. Furthermore, 0.1 and 0.9 quantiles are indicated by red, 0.2 and 0.8 by orange, 0.3 and 0.7 by yellow, 0.4 and 0.6 by yellow-green, and 0.5 by green lines.

Table 5. Determination of the optimal number of hidden layers and the appropriate number of neurons in the hidden layer.

\begin{tabular}{|c|c|c|c|}
\hline Hidden Layer & Neurons ${ }^{1}$ & MAE $^{2}$ & Computation Time (s) \\
\hline \multirow{4}{*}{2} & 4 & 16.528711 & $10 \mathrm{~s}$ \\
\hline & 8 & 16.545627 & $10 \mathrm{~s}$ \\
\hline & 16 & 16.787603 & $11 \mathrm{~s}$ \\
\hline & 32 & 16.524037 & $15 \mathrm{~s}$ \\
\hline \multirow{4}{*}{3} & 4 & 16.499576 & $12 \mathrm{~s}$ \\
\hline & 8 & 16.391850 & $12 \mathrm{~s}$ \\
\hline & 16 & 16.671966 & $13 \mathrm{~s}$ \\
\hline & 32 & 16.369946 & $17 \mathrm{~s}$ \\
\hline \multirow{4}{*}{4} & 4 & 16.201253 & $14 \mathrm{~s}$ \\
\hline & 8 & 16.292288 & $15 \mathrm{~s}$ \\
\hline & 16 & 16.193952 & $15 \mathrm{~s}$ \\
\hline & 32 & 16.668355 & $17 \mathrm{~s}$ \\
\hline \multirow{4}{*}{5} & 4 & 16.218435 & $15 \mathrm{~s}$ \\
\hline & 8 & 16.382307 & $15 \mathrm{~s}$ \\
\hline & 16 & 16.237098 & $18 \mathrm{~s}$ \\
\hline & 32 & 16.383952 & $20 \mathrm{~s}$ \\
\hline
\end{tabular}

${ }^{1}$ The number of neurons each hidden layer, ${ }^{2}$ mean absolute error. 


\subsubsection{Evaluation}

Table 6 lists the performance evaluation results of quantile GAMs and QRNN models. All quantile loss values were derived according to 0.1-0.9 fitting lines of AIS information for each phase. The result of comparing the average value of the loss for each quantile was visualized as a bar plot, as shown in Figure 8. In general, the loss value of QRNN was analyzed to achieve better performance than that of the GAMs. The analysis result indicates that the GAMs and QRNN model is suitable for analysis and is feasible for use as a guideline for safe ship operation based on ship trajectories. However, the QRNN model can yield slightly more accurate results than GAMs.

Table 6. The evaluation result of regression model according to quantile loss.

\begin{tabular}{|c|c|c|c|c|c|c|c|c|c|c|c|c|}
\hline \multirow{2}{*}{ Model } & \multirow{2}{*}{ Phase } & \multirow{2}{*}{ Information } & \multicolumn{9}{|c|}{ Quantile } & \multirow{2}{*}{ Total } \\
\hline & & & 0.1 & 0.2 & 0.3 & 0.4 & 0.5 & 0.6 & 0.7 & 0.8 & 0.9 & \\
\hline \multirow{9}{*}{$\begin{array}{l}\text { Quantile } \\
\text { GAMs }\end{array}$} & \multirow{3}{*}{ Entering Phase } & SOG & 5.465 & 7.046 & 7.877 & 8.267 & 8.283 & 7.960 & 7.261 & 6.093 & 4.174 & 6.936 \\
\hline & & COG & 6.238 & 6.807 & 6.998 & 6.944 & 6.686 & 6.221 & 5.516 & 4.521 & 3.203 & 5.904 \\
\hline & & LONG & 14.398 & 15.429 & 16.162 & 16.752 & 17.249 & 17.666 & 17.997 & 18.220 & 18.262 & 16.904 \\
\hline & \multirow{4}{*}{ Left } & SOG & 20.124 & 19.827 & 18.600 & 16.870 & 14.796 & 12.425 & 9.786 & 6.874 & 3.692 & 13.666 \\
\hline & & COG & 2.568 & 3.386 & 4.118 & 4.796 & 5.426 & 6.012 & 6.547 & 7.010 & 7.353 & 5.246 \\
\hline & & LONG & 3.993 & 7.726 & 11.328 & 14.822 & 18.212 & 21.480 & 24.590 & 27.447 & 29.815 & 17.713 \\
\hline & & SOG & 28.796 & 28.128 & 26.381 & 24.119 & 21.501 & 18.604 & 15.441 & 11.963 & 8.040 & 20.330 \\
\hline & \multirow[t]{2}{*}{ Right } & COG & 3.233 & 3.552 & 3.611 & 3.536 & 3.366 & 3.108 & 2.750 & 2.253 & 1.485 & 2.988 \\
\hline & & LONG & 6.310 & 9.582 & 12.368 & 15.529 & 18.308 & 20.974 & 23.502 & 25.841 & 27.799 & 17.801 \\
\hline \multirow{9}{*}{ QRNN } & \multirow{3}{*}{ Entering Phase } & SOG & 4.503 & 6.336 & 7.467 & 8.026 & 8.196 & 7.932 & 7.221 & 5.463 & 3.247 & 6.488 \\
\hline & & COG & 5.785 & 6.797 & 7.077 & 6.945 & 6.359 & 5.747 & 4.898 & 3.831 & 2.305 & 5.527 \\
\hline & & LONG & 13.035 & 14.716 & 15.608 & 16.345 & 16.885 & 17.403 & 17.836 & 18.084 & 18.166 & 16.453 \\
\hline & \multirow{6}{*}{$\begin{array}{l}\text { Berthing } \\
\text { Phase }\end{array}$} & SOG & 17.964 & 18.230 & 17.706 & 16.726 & 15.561 & 13.531 & 10.633 & 7.359 & 3.978 & 13.521 \\
\hline & & $\mathrm{COG}$ & 2.431 & 3.309 & 4.123 & 4.840 & 5.446 & 5.878 & 6.168 & 6.712 & 7.418 & 5.147 \\
\hline & & LONG & 4.224 & 8.098 & 11.491 & 14.836 & 18.253 & 21.472 & 24.216 & 26.734 & 28.745 & 17.563 \\
\hline & & SOG & 27.056 & 26.949 & 25.644 & 23.889 & 21.625 & 18.536 & 15.409 & 11.951 & 7.963 & 19.891 \\
\hline & & COG & 2.179 & 2.815 & 3.001 & 2.990 & 3.093 & 2.846 & 2.438 & 1.935 & 1.166 & 2.496 \\
\hline & & LONG & 5.829 & 9.398 & 12.511 & 15.381 & 18.121 & 20.724 & 23.185 & 25.339 & 26.972 & 17.496 \\
\hline
\end{tabular}

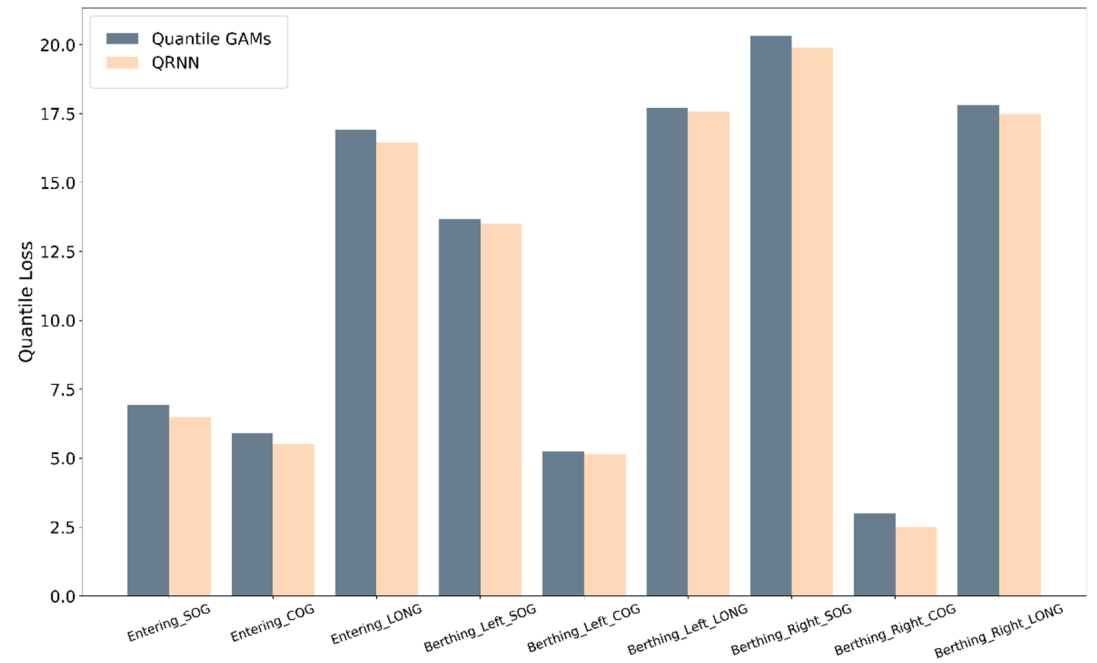

Figure 8. Result of visualizing the comparison of the average values of loss by quantiles as a bar plot: GAMs and QRNN model.

\section{Discussion}

Ship trajectory data were analyzed using quantile regression-based GAMs and a QRNN for the safe operation of ships in ports. This methodology is meaningful because it proposes the ship maneuvering method in the port as a data-based quantitative numerical value, unlike the traditional system of handing down the information in an apprentice system among pilots. Thus, this methodology presents a new approach to ship trajectory data analysis. 
Because the quantile regression used in the study can effectively process data, including variability and uncertainty, it is suitable for analyzing the data of ships with various trajectories according to weather conditions and traffic flow. In addition, because regression by quantiles is possible, the operating range for ship maneuvering can be suggested, making the method effective for suggesting guidelines. Thus, the quantile regression model in this study proposes safe navigation guidelines, such as COG operation within the 10-quantile to 90-quantile range and SOG operation within the 40-quantile to 60-quantile range, based on the port situation. According to the analysis results, the performance of the QRNN model is better than that of GAMs, but both methodologies can be used. GAMs have the advantage of providing results using a smooth fitting line as a smoothing function, and the QRNN is complex but provides accurate analysis results based on datasets. Figure 9a shows an example of the use of guidelines for the ship's position. In particular, it is possible to use these guidelines by plotting them on the Electronic Chart Display and Information System used in ships. In addition, linking the SOG and COG data, as shown in Figure 9b, will be helpful for the safe operation of ships by referring to the operating range at the relevant location.

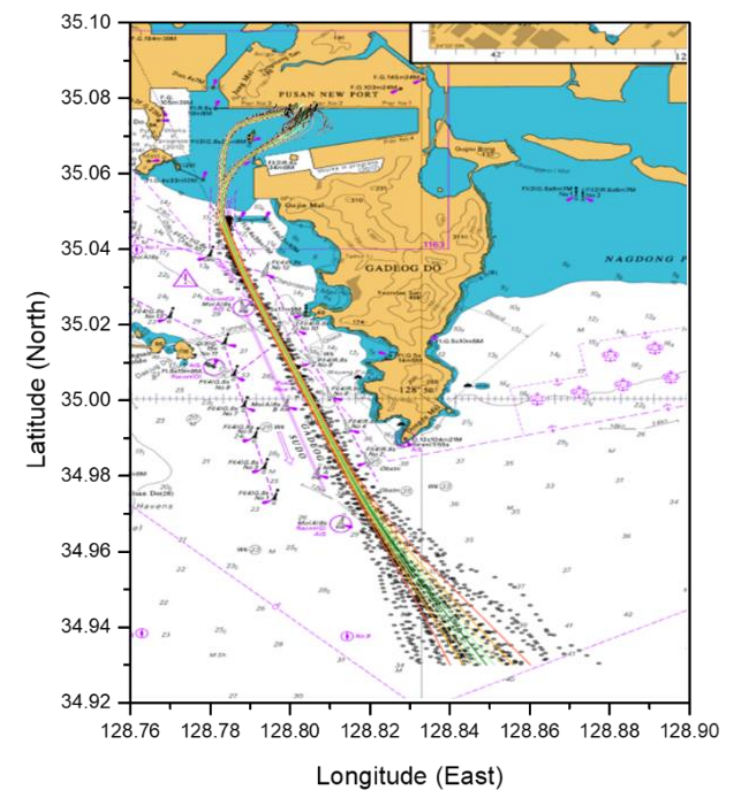

(a)

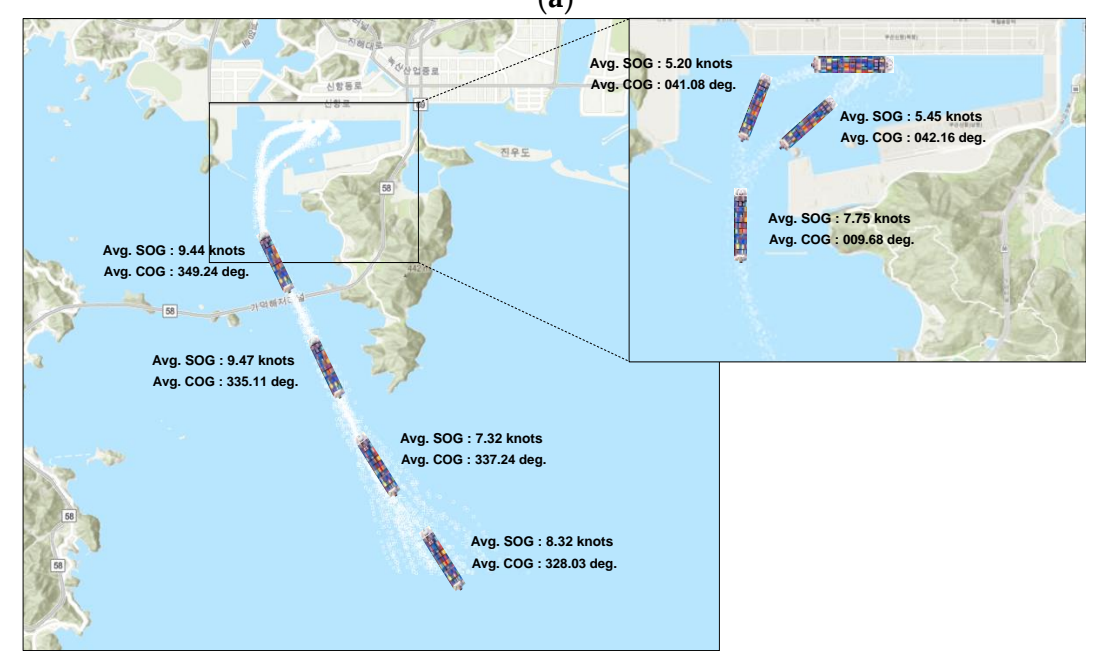

(b)

Figure 9. Example of using ship maneuvering guidelines in port: (a) ship's position guidelines; (b) speed over ground and course over ground guidelines. 
The long-term utilization aspect of this study can be presented as a basic study related to the port operation of maritime autonomous surface ships (MASSs). Although many studies have dealt with autonomous navigation techniques in the ocean, relatively few have explored the autonomous navigation of ships in ports [16]. Therefore, various approaches based on data-based machine learning and artificial intelligence are required for autonomous ship operation in ports, and the results of this study can serve as basic data. Moreover, combining this study with research on the berthing of ships can provide the key to the connection technology between MASSs and ports [42,43].

\section{Conclusions and Future Work}

Quantile regression-based GAMs and a QRNN were applied for realizing guidelines for safe ship operation in ports using AIS-based ship trajectory data. The novelty of this work is that the SOG, COG, and ship's position information can be analyzed by quantile regression to utilize the ship's operating guidelines. Traditional statistical models based on mean values cannot interpret ship trajectory data with variability and uncertainty. A ship's trajectory changes because of weather, traffic flow, and the pilot's operation; however, the ships are safely berthed to complete the operation in the port. Therefore, proposing ship operation guidelines based on average values is subject to significant error. Due to the limitations of traditional statistical analysis, this study analyzed ship trajectory data via quantile regression analysis. This approach examines changes in SOG, COG, and other metrics with respect to the ship's position via quantiles and can determine the ship's maneuvering guideline range based on port conditions.

However, only the ship trajectory data of one port, i.e., Busan New Port, were used in this study. Hence, it is necessary to analyze various port and ship types, including a range ships' sizes. Further, the performance of GAMs and the QRNN algorithm should be improved for safe maneuvering guidelines in the future. Data reliability should be further increased by collecting data for a long period of time, and additional research on the operator behavior and ship operation patterns according to the weather is necessary.

Author Contributions: Conceptualization, H.-T.L. and I.-S.C.; methodology, H.-T.L. and H.Y.; software, H.-T.L. and H.Y.; validation, H.-T.L., H.Y. and I.-S.C.; formal analysis, H.-T.L.; investigation, H.-T.L.; data curation, H.-T.L. and I.-S.C.; writing-original draft preparation, H.-T.L.; writingreview and editing, H.-T.L., H.Y. and I.-S.C.; visualization, H.-T.L.; supervision, H.Y. and I.-S.C.; All authors have read and agreed to the published version of the manuscript.

Funding: This research was a part of the project titled "Development of Smart Port-Autonomous Ships Linkage Technology", funded by the Ministry of Oceans and Fisheries, Korea.

Institutional Review Board Statement: Not applicable.

Informed Consent Statement: Not applicable.

Data Availability Statement: Restriction apply to the availability of these data. Data were obtained from the Busan Port Authority.

Acknowledgments: This research was supported by the Development of Smart Port-Autonomous Ships Linkage Technology, funded by the Ministry of Oceans and Fisheries. And this research was conducted with the provided dataset from the Busan Port Authority.

Conflicts of Interest: The authors have no conflict of interest to declare.

\section{References}

1. Sur, J.M.; Kim, D.J. Comprehensive risk estimation of maritime accident using fuzzy evaluation method-Focusing on fishing vessel accident in Korean waters. Asian J. Shipp. Logist. 2020, 36, 127-135. [CrossRef]

2. Kim, C.H.; Park, Y.S.; Kim, D.W. A Study on the safety measure for mega container Ship's calling at Busan new port from the perspective of pilotage. J. Navig. Port Res. 2015, 44, 174-180.

3. KMST. Maritime Accidents Special Investigation Report-Crane Collision Accident of Container Ship; Technical Report for Marine Accident Investigation; Marine Accident Investigation: Sejong, Korea, 2020. 
4. Perkovič, M.; Gucma, L.; Bilewski, M.; Muczynski, B.; Dimc, F.; Luin, B.; Vidmar, P.; Lorenčič, V.; Batista, M. Laser-based aid systems for berthing and docking. J. Mar. Sci. Eng. 2020, 8, 346. [CrossRef]

5. Lee, H.T.; Lee, J.S.; Cho, J.W.; Yang, H.; Cho, I.S. A Study on the Pattern of Pilot's Maneuvering using K-means Clustering of Ship's Berthing Velocity. J. Coas.T Disaster Prev. 2020, 7, 221-232. [CrossRef]

6. Ji, Y.; Wang, L.; Wu, W.; Shao, H.; Feng, Y. A method for LSTM-based trajectory modeling and abnormal trajectory detection. IEEE Access 2020, 8, 104063-104073. [CrossRef]

7. Zhang, L.; Meng, Q.; Xiao, Z.; Fu, X. A novel ship trajectory reconstruction approach using AIS data. Ocean. Eng. 2018, 159, 165-174. [CrossRef]

8. Lee, J.S.; Son, W.J.; Lee, H.T.; Cho, I.S. Verification of novel maritime route extraction using kernel density estimation analysis with automatic identification system data. J. Mar. Sci. Eng. 2020, 8, 375. [CrossRef]

9. Son, W.J.; Lee, J.S.; Lee, H.T.; Cho, I.S. An investigation of the ship safety distance for bridges across waterways based on traffic distribution. J. Mar. Sci. Eng. 2020, 8, 331. [CrossRef]

10. Huang, J.C.; Nieh, C.Y.; Kuo, H.C. Risk assessment of ships maneuvering in an approaching channel based on AIS data. Ocean Eng. 2019, 173, 399-414. [CrossRef]

11. Namgung, H.; Kim, J.S. Vessel trajectory analysis in designated harbor route considering the influence of external forces. J. Mar. Sci. Eng. 2020, 8, 860. [CrossRef]

12. Suo, Y.; Chen, W.; Claramunt, C.; Yang, S.A. A Ship trajectory prediction framework based on a recurrent neural network. Sensors 2020, 20, 5133. [CrossRef] [PubMed]

13. Gao, D.W.; Zhu, Y.S.; Zhang, J.F.; He, Y.K.; Yan, K.; Yan, B.R. A novel MP-LSTM method for ship trajectory prediction based on AIS data. Ocean. Eng. 2021, 228, 108956. [CrossRef]

14. Zhang, D.; Zhang, Y.; Zhang, C. Data mining approach for automatic ship-route design for coastal seas using AIS trajectory clustering analysis. Ocean. Eng. 2021, 236, 109535. [CrossRef]

15. Wang, L.; Chen, P.; Chen, L.; Mou, J. Ship AIS trajectory clustering: An HDBSCAN-based approach. J. Mar. Sci. Eng. 2021, 9, 566. [CrossRef]

16. Lee, H.T.; Lee, J.S.; Yang, H.; Cho, I.S. An AIS data-driven approach to analyze the pattern of ship trajectories in ports using the DBSCAN algorithm. Appl. Sci. 2021, 11, 799. [CrossRef]

17. Rong, H.; Teixeira, A.P.; Guedes Soares, C.G. Data mining approach to shipping route characterization and anomaly detection based on AIS data. Ocean. Eng. 2020, 198, 106936. [CrossRef]

18. Choi, K.Y.; Lee, D.S.; Park, Y.S. A study on the analysis of present navigation method at the Ulsan waterways from the viewpoint of pilot. J. Navig. Port Res. 2011, 35, 469-475. [CrossRef]

19. DinparastDjadid, A.; Lee, J.D.; Domeyer, J.; Schwarz, C.; Brown, T.L.; Gunaratne, P. Designing for the extremes: Modeling drivers' response time to take back control from automation using Bayesian quantile regression. Hum. Factors 2021, 63, 519-530. [CrossRef] [PubMed]

20. Zou, Y.; Tang, J.; Wu, L.; Henrickson, K.; Wang, Y. Quantile analysis of factors influencing the time taken to clear road traffic incidents. Transp. 2017, 170, 296-304. [CrossRef]

21. Murphy, R.R.; Perry, E.; Harcum, J.; Keisman, J. A generalized additive model approach to evaluating water quality: Chesapeake bay case study. Environ. Modell. Softw. 2019, 118, 1-13. [CrossRef]

22. Dinga, R.; Fraza, C.J.; Bayer, J.M.; Kia, S.M.; Beckmann, C.F.; Marquand, A.F. Normative modeling of neuroimaging data using generalized additive models of location scale and shape. bioRxiv 2021. [CrossRef]

23. Deng, Z.; Wang, B.; Guo, H.; Chai, C.; Wang, Y.; Zhu, Z. Unified quantile regression deep neural network with time-cognition for probabilistic residential load forecasting. Complexity 2020, 2020, 9147545. [CrossRef]

24. Gan, D.; Wang, Y.; Yang, S.; Kang, C. Embedding based quantile regression neural network for probabilistic load forecasting. J. Mod. Power Syst. Clean Energy 2018, 6, 244-254. [CrossRef]

25. Jia, Y.; Jeong, J.H. Deep learning for quantile regression under right censoring: DeepQuantreg. Comp. Stat. Data Anal. 2021, 107323. Available online: https:/ / arxiv.org/abs/2007.07056 (accessed on 9 December 2021).

26. Yoon, J.D.; Yun, J.H.; Lee, C.K. A study on the method of conducting a large container vessel safely to the newly built container pier to get alongside in Busan Harbour. J. Korean Soc. Mar. Environ. Saf. 2007, 13, 147-153.

27. Han, J.; Pei, J.; Kamber, M. Data Preprocessing. In Data Mining: Concepts and Techniques, 3rd ed.; Elsevier: Waltham, MA, USA, 2011; pp. 83-124.

28. Series, M. Technical characteristics for an automatic identification system using time-division multiple access in the VHF maritime mobile band. In Recommendation M.1371; International Telecommunication Union: Geneva, Switzerland, 2014. Available online: https: / / www.itu.int/dms_pubrec/itu-r/rec/m/R-REC-M.1371-5-201402-I!!PDF-E.pdf (accessed on 9 December 2021).

29. Kim, D.Y.; Hong, T.H.; Jeong, J.S.; Lee, S.J. Building an algorithm for compensating AIS error data. J. Korean Inst. Intell Syst. 2014, 24, 310-315.

30. Olinsky, A.; Chen, S.; Harlow, L. The comparative efficacy of imputation methods for missing data in structural equation modelling. Eur. J. Oper. Res. 2003, 151, 53-79. [CrossRef]

31. Koenker, R.; Bassett, G. Regression quantiles. Econometrica 1978, 46, 33-50. [CrossRef]

32. Cannon, A.J. Quantile regression neural networks: Implementation in R and application to precipitation downscaling. Comput. Geosci. 2011, 37, 1277-1284. [CrossRef] 
33. Koenker, R.; Park, B.J. An interior point algorithm for nonlinear quantile regression. J. Econ. 1996, 71, 265-283. [CrossRef]

34. Saerens, M. Building cost functions minimizing to some summary statistics. IEEE Trans. Neural Netw. 2000, 11, $1263-1271$. [CrossRef]

35. Faraway, J.J. Extending the linear model with R: Generalized linear, mixed effects and nonparametric regression models. J. Am. Stat. Assoc. 2007, 102, 1477. [CrossRef]

36. Yee, T.W.; Mitchell, N.D. Generalized additive models in plant ecology. J. Veg. Sci. 1991, 2, 587-602. [CrossRef]

37. Lee, D.; Baldick, R. Short-term wind power ensemble prediction based on Gaussian processes and neural networks. IEEE Trans. Smart Grid 2013, 5, 501-510. [CrossRef]

38. Jia, Y.; Jeong, J.H. Deep learning for quantile regression: DeepQuantreg. arXiv 2020, arXiv:2007.07056. Available online: https: / / ui.adsabs.harvard.edu/abs/2020arXiv200707056J /abstract (accessed on 9 December 2021).

39. Clevert, D.A.; Unterthiner, T.; Hochreiter, S. Fast and accurate deep network learning by exponential linear units (ELUs). arXiv 2015, arXiv:1511.07289.

40. Ruder, S. An overview of gradient descent optimization algorithms. arXiv 2016, arXiv:1609.04747.

41. Xu, Q.; Zhang, J.; Jiang, C.; Huang, X.; He, Y. Weighted quantile regression via support vector machine. Expert Syst. Appl. 2015, 42, 5441-5451. [CrossRef]

42. Lee, H.T.; Lee, J.S.; Son, W.J.; Cho, I.S. Development of machine learning strategy for predicting the risk range of Ship's berthing velocity. J. Mar. Sci. Eng. 2020, 8, 376. [CrossRef]

43. Lee, H.T.; Lee, S.W.; Cho, J.W.; Cho, I.S. Analysis of feature importance of ship's berthing velocity using classification algorithms of machine learning. J. Korean Soc. Mar. Environ. Saf. 2020, 26, 139-148. [CrossRef] 